system and cytochrome oxidase were definitely observed though weak in activity, while DPN- and TPN- diaphorases were more active with lactate, glucose-6phosphate or 6-phosphogluconate as substrates than with isocitrate or malate. c. Activities of gland cells and duct system

Leucine aminopeptidase, TPN-diaphorase, phosphorylase activities were observed not only in the gland cells but also in the duct sytem in which stronger activities were demonstrated than the acinar cells. It was discussed that the duct system played an individual metabolism different from the acinar cells. d. Monoamine oxidase activity

Monoamine oxidase activity has attracted attension of neurologists and pharmacologists in recent years. In the human lacrimal gland, weak monoamine oxidase activity was detected in the myoepithlial cells. This might indicate the presence of metabolic field for catecholamines in the acinar cells.

e. Other hydrolytic enzymes

Excepting the above-mentioned enzymes, acid phosphatase, esterase, $\boldsymbol{\beta}$-glucuronidase, $\beta$-galactosidase, activities were detected in the acinar cells as well as in the duct system. Activities of these enzymes will be further investigated from the viewpoint of biochemical cytology.

\title{
References
}

1) Yuge, T. : Acta O. Jap., $40: 889,1936.2$ 2) Kobayashi, M, : Acta O. Jap., $62: 2208$, 1958. 3) Kato, Y. : Acta O. Jap., $62: 175,1958 . \quad$ 4) Leeson, C. R. : Acta Anat., $40: 87$, 1960. 5) Takagi, Y. and Kamada, K. : Acta O. Jap., $57: 155,1961 . \quad 6)$ Mizukawa, T. Otori, T., Hara, J. and Morisue, T. : Acta O. Jap. 65:1247, 1961. 7) Mizukawa, T., and Otori, T. : Folia O. Jap., $12: 317,1961$.

\section{The Development of Dopa Oxidase Activity in the Skin and in the Hair Cycle}

\author{
Ken Hashimoto, Kazuo Ogawa, and Walter F. Lever \\ The Department of Anatomy, Kyoto University, School of Medicine, Kyoto, the Department \\ of Dermatology, Niigata University, School of Medicine, Niigata, and the Department \\ of Dermatology, Tufts University, School of Medicine, Boston
}

Although several authors have investigated the embryonic development of the melanocytes and of dopa oxidase activities in mammals ${ }^{1-6)}$ and in human fetuses $^{6 \sim 11}$, in this field of research a closely graded series of early embryos is of great value in following the rapid migration and maturation of melanocytes. For this purpose, a number of mice were used at various stages of their development and the entire sequence of pigment cell development was followed 
from the earliest stage to the adult stage in the skin and hair follicles. In addition, the regeneration of melanocytes and, in particular, the enzymatic activity of the regenerating melanocytes were studied in hair regrowing after plucking and this process was compared with the natural process of melanocyte maturation in embryogenesis.

\section{Materials and Methods}

Animal Materials. Fifteen mice embryos (3 each on the 10th, 12th, 14th, 16 th and 18th days of gestation), 12 young mice (3 each on the 1 st, 5 th, 10 th and 15 th days of birth) and 10 adult mice weighing approximately $60 \mathrm{~g}$ were used. All mice used were of $\mathrm{C} 57 \mathrm{BL} / 6$ strain which has black hair but a white skin. In some of the adult mice hairs were plucked from the back and upper lip to initiate a new hair cycle. These mice were killed on the $1 \mathrm{st}, 3 \mathrm{rd}$, 4 th, 6 th, 8 th or 18 th day after plucking, at which time the follicles were in various stages of regeneration, i.e., in anagen I to $I^{{ }^{12}{ }^{13)}}$. New-born and older mice were killed by a blow on the neck without anesthesia. Skin then was taken from the back and upper lip, and the hair was shaven off. In embryos skin was taken from the same areas, while they were still alive. All skin specimens were sectioned at 15 to $20 \mu$ in a microtome cryostat at $-15^{\circ} \mathrm{C}$ and were immediately incubated as floating sections in both substrate and control media. A portion of each skin specimen was fixed in formol-calcium for the ammoniated silver nitrate stain for melanin of Fontana ${ }^{14}$.

Histochemical Methods for the Demonstration of Dopa Oxidase. The dopa oxidase stain originally designed for paraffin sections by Becker et al. ${ }^{15}$ and modified by Pearse ${ }^{14}$ for use on frozen sections was applied. Sections were incubated for varying periods of time, usually for 3 to 4 hours.

Control and Inhibition Studies. Substrate-free media were used for control. Potassium cyanide in a final concentration of $10^{-3} \mathrm{M}$ was added to the incubation media as an inhibitor of the dopa oxidase.

Other Stain. Fontana's ammoniated silver nitrate method for melanin ${ }^{14}$, was used.

\section{Results and Discussion}

Premature Melanocytes and Propigment. In the 10-day-old embryo the earliest stage of melanocytes was observed. They appeared as round or oval cells with few dendrites and were loaded with faintly brown granules which stained with the Fontana stain. None of these cells, however, gave a positive dopa oxidase reaction, which did not become positive in them until about the 14 th day of gestation. Becker and Zimmermann ${ }^{9)}$ have reported a considerable difference in the number of stainable melanocytes in early Negro fetus depending on whether Masson's ammoniated silver nitrate technique or von Kossa's silver impregnation method was used: more melanocytes were revealed with Masson's stain than with von Kossa's stain. They concluded that Masson's stain brought into evidence not only mature but also premature melanocytes containing "propigment" or "premelanin granules", while von Kossa's method 
stained only the melanin of mature melanocytes. Zimmermann ${ }^{16)}$ also has stated that Masson's method revealed melanocytes before they became dopa positive. It is likely that the melanocytes with faintly brown pigment granules but without a positive dopa reaction, as found in 10 to 12-day-old embryos, correspond to the "propigment" (or premelanin) of Becker and Zimmermann". However, the possibility exists that these premature melanocytes which have already formed propigment or pregranules do possess dopa oxidase activity but that our present methods are not sensitive enough to detect the faint beginning of the enzyme activity ${ }^{10}$.

Migration of Melanocytes in the Dermis. Beginning with the first detection of dopa negative melanocytes in the loosely-knit mesenchymal tissue of the 10-day-old mouse embryo, the number of dopa-negative and later dopapositive melanocytes diffusely distributed in the dermis increased steadily up to about the 16 th day of gestation, at which time the melanocytes began to aggregate around the upper portion of tactile hairs and in the upper dermis. In 18-day-old embryos the number of melanocytes in the hair bulbs of tactile hair and of coat hair had also markedly increased. Concurrently, the number of melanocytes lying free in the dermis had became smaller. Thus the impression was gained that melanocytes migrated from their scattered location in the dermis to the young hair bulbs. Although the decrease in the number of free dermal melanocytes resulted mainly from their migration to the hair bulbs and to the upper dermis, some of the decrease was due also to the expansion of the skin during the early postnatal days. This temporary diffuse distribution of young melanocytes in the dermis in mouse embryo appeared similar to the permanent layer of melanocytes seen in the dermis of anthropoid apes and of some monkeys ${ }^{17}$ ) and in the Mongolian spots of humans. Zimmermann and Becker ${ }^{18)}$ observed in human fetus similar accumulation of melanocytes in the scalp and in the skin on the dorsum of hands and feet. They explained their inability to demonstrate the presence of melanocytes in all other skin areas as being due to the loss of enzymatic activity in these melanocytes.

Dopa Oxidase Activity During the Regeneration of Hair. Following the plucking of a hair, only a few shrunken melanocytes left behind in the hair papilla showed a weakly positive dopa oxidase reaction from the first to the fourth day after plucking (anagen I through anagen III). On the fifth day enzyme activity appeared in regenerating melanocytes in the growing hair bulb. The regeneration of the hair and the reappearance of enzymatic activity in the melanocytes of the hair bulb occurred earlier in tactile than in coat hair. This is in line with the faster embryonic development of tactile hair and the earlier appearance of enzymatic activity in the melanocytes of its hair bulb. The data obtained by Fitzpatrick et al. in C $57 \mathrm{BL} / 6$ mice $^{19}$ ) on the regeneration of coat hair and the reappearance of enzymatic activity are in essential agreement with the present data, except that Fitzpatrick el al. did not mention any persistence of the dopa reaction in the melanocytes left behind in the hair papilla from the previous hair cycle. Chase ${ }^{20)}$ observed some pigment aggregates in a "hair germ", but he did not mention the presence 
of dopa oxidase activity either.

Comparing the time required for embryonic hair to grow with the time required for hair to regenerate after plucking, it is apparent that embryonic hair growth is a much slower process than hair regeneration. For instance, if the developmental stage of the coat hair in a 14-day-old embryo is taken as comparable with that of anagen I (because in both cases the hairs start to grow), then the growth stage of the coat hair in a 5-day-old mouse is roughly comparable with anagen IV. Thus the same amount of hair growth which took the coat hair 11 days in the embryonic stage was achieved in only 5 days during the regeneration process after plucking. Since the development of the melanocytes and of their enzymatic activity goes parallel to the structural development of the hair, it also follows that regeneration of melanocytes and of their enzymatic activities after plucking of the hair proceeds much faster than their development in embryonic life.

\section{Summary}

1. The development of melanocytes and of their dopa oxidase activity was followed in mice embryos and was compared with the regeneration of melanocytes and their dopa oxidase activity during anagen I to IV.

2. Melanocytes with dopa-negative "propigment granules" were already present in 10-day-old embryos in the loosely-knit mesenchymal tissue of the skin. These premature melanocytes were round to oval and sometimes dendritic. Dopa oxidase activity first became apparent in the dermal melanocytes and in those of tactile hair bulbs in 14-day-old embryos. The enzyme reaction gradually increased in intensity as the melanocytes enlarged and became more dendritic. Melanocytes began to inoculate melanin granules into tactile hairs in the 18-day-old embryo, and into coat hairs in the new-born mouse.

3. The number of melanocytes lying free in the dermis increased until about the 16 th day of gestation. Thereafter, their number gradually decreased as the melanocytes tended to congregate in the hair bulbs, in the upper dermis and around the upper portion of tactile hairs. In the adult mouse the number of free dermal melanocytes was small.

4. In the hair papilla of the plucked coat hair some dopa-reactive melanocytes remained present in a shrunken form. Regeneration of melanocytes and of their enzymatic activity began 4 days after plucking (anagen III); and a burst of melanocyte regeneration accompanied by intense enzyme activity occurred 6 days after plucking (anagen IV). The speed of regeneration of the coat hair, of its melanocytes and of the dopa oxidase activity in the melanocytes was approximately twice as fast as observed during the embryonic development.

\section{References}

1) De Shane, G.P.: The embryology of vertebrate pigment cells. I. Amphibia. Quart. Rev. Biol., $18: 109-127,1943 . \quad 2)$ Rawles, M. E. : Origin of pigment cells from the neural crest in the mouse embryo. Physiol. Zool., $20: 248-266,1947 . \quad 3) \quad$ : Origin of melanophores and their role in development of color pattern in vertebrates. Physiol. Rev., 
28 : 383-408, 1948. 4) Danneel, R. und Cleffmann, G. : Die Einwanderung der Pigmentzellen in die Haut und die Haare bei Nagetieren. Biol. Zentralbl., 73:414-428, 1954. 5) Zimmermann, A. A. : Die Entwicklung der Hautfarbe beim Neger vor der Geburt. Mitteilungen d. Thurg. Naturforsch. Gesellschaft Switzerland; Heft $37: 33-71,1954$. 6) Danneel, R. und Weissenfels, N. : Die Herkunft der Melanoblasten in den Haaren des Menschen und ihr Verbleib beim Haarwechsel. Biol. Zentralbl., 72:630-643, 1953. 7) Zimmermann, A. A. and Cornbleet, Th. : The development of epidermal pigmentation in the Negro fetus. J. Invest. Dermat., $11: 383-392,1948 . \quad 8)$ Zimmermann, A. A. : The development of epidermal pigmentation in the Negro fetus. Zoologica, $35: 10-12,1950.9$ 9) Becker Jr., S. W. and Zimmermann, A. A. : Further studies on melanocytes and melanogenesis in the human fetus and new-born. J. Invest. Dermat., $25: 103-112,1955 . \quad 10)$ Zimmermann, A. A. and Becker Jr., S. W. : Precursors of epidermal melanocytes in the Negro fetus, in Pigment Cell Biology, ed. by Gordon, Academic Press Inc., New York, 1959. Pages 159-170. 11) Szabo, G : Quantitative histochemical investigations on the melanocyte system of the human epidermis. Ibid. Pages 99-125. 12) Dry, F. W. : The coat of the mouse (Mus musculus). J. Genet. $16: 287-340$, 1926. 13) Chase, H. B., Rauch, H. and Smith, V. W. : Critical stages of hair development and pigmentation in the mouse. Physiol. Zool., $24: 1-8,1951$. 14) Pearse, A. G. E. : Histochemistry, Theoretical and Applied. J. and A. Churchill, Ltd., London, 1960. Pages 524, 905 and 919. 15) Becker Jr., S. W., Praver, L. L., and Thatcher, H. : An improved (paraffin section) method for the DOPA reaction, with considerations of the DOPA-positive cell, as studied by this method. Arch. Derm. and Syph., $31: 190-195,1935.16)$ Zimmermann, A. A.: in the discussion of "Melanocyte system of human epidermis", in Pigment Cell Biology, ed. by M. Gordon, Academic Press Inc., New York, 1959. Page 125. 17) Adachi, B : Hautpigment beim Menschen und bei den Affen. Z. Morphol. u. Anthropol. 6 : 1-131, 1903. 18) Birbeck, M. S. C. and Barnicot, N. A. : Electron microscope studies on pigment formation in human hair follicles, in Pigment Cell Biology, ed. by M. Gordon, Academic Press Inc., New York, 1959. Pages 549-561. 19) Fitzpatrick, T. B., Brunet, P. and Kukita, A. : "The nature of hair pigment", in the Biology of Hair Growth, ed. by W. Montagna and R. A. Ellis, Academic Press Inc., New York, 1958. Pages 255-303. 20) Chase, H. B. : "Behavior of pigment cells and epidermal cells". Ibid. Pages 229-237.

\title{
Histochemistry of Protein Groups
}

\section{A Significance of Alloxan-and Ninhydrin-Schiff Methods for Protein}

\author{
Yasuo DEGUCHI \\ Department of Oral Surgery, Osaka University Dental School, Osaka.
}

\section{Introduction}

The alloxan-and ninhydrin-Schiff methods have been accepted to be the most specific and available reactions in protein histochemistry. ${ }^{1-4)}$ The millon reaction $^{5)}$, the dinitrofluorobenzene $\mathrm{H}$-acid method, ${ }^{4,6)}$ the coupled tetrazonium $\operatorname{method}^{7)}$ and the dimethylaminobenzaldehyde reaction for tryptophane ${ }^{8,9)}$ are also being employed in histochemical detections of proteins, elastic and kollagen fibers, amyloid, ${ }^{10-12)}$ etc. 